\title{
Comparative Pharmacokinetics/Pharmacodynamics of Fixed-Dose Combination of Esomeprazole and Calcium Carbonate (AD-206) to the Conventional Esomeprazole
}

\author{
Sungyeun $\mathrm{Bae}^{\mathrm{I}}$ \\ Jihoon Kwon ${ }^{2}$ \\ Si-Beum Lee $\mathbb{D}^{3}$ \\ In-Jin Jang $(\mathbb{D})^{\prime}$ \\ Kyung-Sang Yu (D) \\ SeungHwan Lee (D) \\ 'Department of Clinical Pharmacology \\ and Therapeutics, Seoul National \\ University College of Medicine and \\ Hospital, Seoul, Republic of Korea; \\ ${ }^{2}$ Statistics Team, APACE, Seoul, Republic \\ of Korea; ${ }^{3}$ Addpharma Pharmaceutical \\ Corp, Seongnam-si, Gyeonggi, Republic \\ of Korea
}

Purpose: Proton pump inhibitors (PPIs) are used for the treatment of acid-related disorders. Demands for enhanced stability and faster onset led to the development of AD-206, a fixeddose combination of a PPI (esomeprazole) with an antacid salt (calcium carbonate). This study compared the pharmacokinetics (PKs) and pharmacodynamics (PDs) of AD-206 (Addpharma) with conventional esomeprazole (Nexium ${ }^{\circledR}$, AstraZeneca).

Materials and Methods: A randomized, open-label, two-treatment, two-sequence crossover study was conducted with 2 different doses of esomeprazole at 20 and $40 \mathrm{mg}$ with a fixed calcium carbonate dose of $600 \mathrm{mg}$ in AD-206. Forty-four subjects were included in each dose group and randomly received either AD-206 or the conventional esomeprazole for 7 consecutive days in each period. After a single- and multiple-dose, blood samples for the PK analysis were analyzed, and 24-hour intragastric $\mathrm{pH}$ monitoring was conducted.

Results: The systemic exposure of esomeprazole after a multiple-dose of AD-206 was similar to that of the conventional esomeprazole in both doses, but the time to reach the peak concentration was faster in AD-206. The percentage decrease from baseline in the integrated gastric acidity for a 24-hour interval after the dose was not significantly different between the AD-206 and the conventional esomeprazole after a single- and multiple-dose for both doses, and the time to reach $\mathrm{pH} 4$ was faster for AD-206.

Conclusion: AD-206 showed a similar systemic exposure and suppression of gastric acid secretion after a multiple-dose compared to the conventional esomeprazole.

Keywords: proton pump inhibitors, randomized controlled study, crossover design, healthy subjects, intragastric $\mathrm{pH}$ monitoring

\section{Introduction}

Gastroesophageal reflux disease (GERD) is defined as a condition where the reflux of gastric content evokes uncomfortable symptoms or complications. ${ }^{1}$ Clinical manifestations of GERD include heartburn, regurgitation and other unclassical symptoms. The prevalence of GERD was found to be approximately $10 \%$ to $20 \%$ in Western countries and $5 \%$ in Asia. ${ }^{2}$

Several drugs of choice are used to treat GERD, one of which is proton pump inhibitors (PPIs). PPIs reduce acid secretion by irreversibly inactivating the gastric $\mathrm{H}+, \mathrm{K}+$-APTase. ${ }^{3}$ PPIs were proven to be more effective in alleviating symptoms and treating complications with a comparable tolerability compared to other options
Department of Clinical Pharmacology and Therapeutics, Seoul National University College of Medicine and Hospital, 10

Daehak-ro, Jongno-gu, Seoul, 03080,

Republic of Korea

Tel +82-2-2072-1920

Fax +82-2-742-9252

Email leejh4I3@snu.ac.kr 
in GERD patients. ${ }^{4-7}$ As a result, PPIs are used as a firstline therapy for GERD in various regions including Korea. $^{8}$ Esomeprazole, the S-isomer of omeprazole, showed an enhanced efficacy with similar tolerability compared to its racemic mixture, omeprazole. ${ }^{9}$ However, esomeprazole is unstable and easily degradable in an acidic condition like other PPIs. ${ }^{10,11}$ Various approaches have been investigated to protect the acid-labile PPIs from degradation by gastric acid, and one of them was to implement an enteric coating including Nexium ${ }^{\circledR}$ (AstraZeneca, England). However, this has delayed their absorption and anti-secretory effects. ${ }^{12}$ Demands for a faster onset of anti-secretory effects led to the development of a PPI combined with an antacid salt. ${ }^{13}$ Zegerid $^{\circledR}$ (Santarus Inc., USA), a combination of omeprazole with sodium bicarbonate $\left(\mathrm{NaHCO}_{3}\right)$, showed a faster absorption and onset of an antisecretory effect compared to the enteric coated omeprazole and was approved by the FDA in 2004. ${ }^{14}$ Since its successful launch, there have been efforts to develop a combination of various PPIs with various antacid salts. $^{15,16}$

AD-206 is a fixed-dose combination of esomeprazole with $600 \mathrm{mg}$ of calcium carbonate $\left(\mathrm{CaCO}_{3}\right)$ developed by Addpharma Pharmaceutical Corp, Korea. This is the first fixed dose combination of PPI with $\mathrm{CaCO}_{3}$ as the antacid counterpart. Considering the acid-neutralizing capacity, a marker to compare the relative effectiveness of antacid preparations, of $\mathrm{CaCO}_{3}$ is $20 \mathrm{mEq} \mathrm{HCl} / \mathrm{g}$ compared to 11.9 $\mathrm{mEq} \mathrm{HCl} / \mathrm{g}$ of $\mathrm{NaHCO}_{3}, \mathrm{AD}-206$ was expected to show similar pharmacokinetic (PK) and pharmacodynamic (PD) features with less amount of the antacid salt compared to other fixed dose combinations of PPIs and $\mathrm{NaHCO}_{3} \cdot{ }^{17,18}$ Therefore, this study compared the PK/PD characteristics of AD-206 (test treatment, T) to the conventional esomeprazole $\left(\right.$ Nexium ${ }^{\circledR}$, reference treatment, R).

\section{Methods}

This study was approved by the Institutional Review Board (IRB) of Seoul National University Hospital. This study was conducted in accordance with the Declaration of Helsinki and Korean Good Clinical Practice (KGCP) (ClinicalTrials.gov identifier: NCT03980756). Due to the confidentiality issue, individual data will not be shared. The first subject was enrolled on July 10, 2019 and the last subject finished the schedule on June 18, 2020. The written informed consents were obtained from all subjects before any study-related procedures.

\section{Study Population}

Healthy Korean subjects aged between 19 and 50 years with a body weight of 50 to $90 \mathrm{~kg}$ and a body mass index (BMI) of 18 to 27 were enrolled. Previous medical and surgical history, physical examination, vital signs, 12-lead electrocardiography (ECG) and clinical laboratory tests were evaluated. Subjects with a past medical history that could influence the PK/PD of esomeprazole including gastrointestinal surgery, history of allergy to esomeprazole or other medications, any anatomical defects that can disturb the insertion or maintenance of a $\mathrm{pH}$ meter catheter, eating habits that can influence the PK/PD of esomeprazole and laboratory tests of $H$. pylori positive or AST/ALT exceeding 1.5 upper limits of normal were excluded.

\section{Study Design}

This study was a randomized, open-label, two-treatment study with 2 different doses. In the $20 \mathrm{mg}$ dose group, AD206, $20 \mathrm{mg}$ of esomeprazole with $600 \mathrm{mg}$ of $\mathrm{CaCO}_{3}$, was compared with the conventional esomeprazole $20 \mathrm{mg}$. In the $40 \mathrm{mg}$ dose group, AD-206, $40 \mathrm{mg}$ of esomeprazole with $600 \mathrm{mg}$ of $\mathrm{CaCO}_{3}$, was compared with the conventional esomeprazole $40 \mathrm{mg}$. Subjects were randomly assigned to one of the two sequences (T-R or R-T) in 1:1 ratio and administered either a test or reference treatment for 7 consecutive days in each period. During PD evaluation, subjects were monitored to ensure they started their standardized meals exactly 4.5 and 10.5 hours after administration and were recommended to eat all the food provided.

\section{Pharmacokinetic Evaluation}

Blood samples for PK evaluation of esomeprazole were collected at 0 (before dosing), 0.17, 0.33, 0.5, 0.75, 1, 1.25, $1.5,2,2.5,3,3.5,4,5,6,8,10,12$ and 24 hours after the single dose (Day 1 ) and at steady state after a multiple dose (Day 7) for each period. For each blood sampling, $5 \mathrm{~mL}$ of blood was collected in a K2-EDTA tube and centrifuged at $4^{\circ} \mathrm{C}$ and $3000 \mathrm{rpm}$ for 10 minutes, and the supernatant was stored at $-70^{\circ} \mathrm{C}$ until analysis. The plasma concentrations of esomeprazole were measured using ultra-performance liquid chromatography-tandem mass spectrometry (UPLC-MS /MS) with esomeprazole-d3 sodium salt as the internal standard. The mass spectrometer was operated in the positive ion mode, and the mass transition ion pair was selected with the mass-to-charge ratio $(\mathrm{m} / \mathrm{z})$ at $346.1 \rightarrow 198.1$ for esomeprazole and $349.1 \rightarrow 198.1$ for the internal standard. The lower 
limit of quantification (LLOQ) was $10 \mathrm{ng} / \mathrm{mL}$. The percentage of the deviation of the mean from theoretical (\% DMT) and the percentage of the relative standard deviation ( $\%$ RSD) of the calibration standard and the quality control sample were within $\pm 15 \%$ ( $\pm 20 \%$ for LLOQ) and met the predetermined criteria for accuracy and precision over the quantification range.

The PK parameters were estimated by noncompartmental methods using the Phoenix WinNonlin ${ }^{\circledR}$ software version 7.0 (Pharsight Co, Mountain View, CA, USA) and included maximum esomeprazole plasma concentration $\left(\mathrm{C}_{\max }\right)$, time to reach $\mathrm{C}_{\max }\left(\mathrm{T}_{\max }\right)$, time point immediately prior to the first quantifiable concentration $\left(t_{\text {lag }}\right)$, area under the concentration-time curve (AUC) within a dosing interval $\left(\mathrm{AUC}_{\mathrm{tau}}\right)$ calculated by the linearup/log-down trapezoidal method, half-life $\left(t_{1 / 2}\right)$, apparent total clearance $(\mathrm{CL} / \mathrm{F})$ and apparent volume of distribution $(\mathrm{Vz} / \mathrm{F})$ after a single- and multiple-dose.

\section{Pharmacodynamic Evaluation}

Intragastric $\mathrm{pH}$ monitoring was performed using an impedance-pH recorder (Digitrapper ${ }^{\mathrm{TM}} \mathrm{pH}-\mathrm{Z}$ recorder, Medtronic Co. Ltd., Ireland). The 24-hour $\mathrm{pH}$ monitoring was performed one day before the first dose (Day -1) for baseline evaluation and after the single (Day 1) and multiple dose (Day 7) for each period. Because subjects received either a test or reference treatment with $150 \mathrm{~mL}$ of water under a fasting condition, the same amount of water was also given in the baseline evaluation. During the 24-hour $\mathrm{pH}$ monitoring, subjects were required to maintain an upright posture at least a 45 -degree angle from $7 \mathrm{AM}$ to $11 \mathrm{PM}$.

The PD parameters included the integrated gastric acidity, time to reach $\mathrm{pH} \geq 4$, percentage of time with gastric $\mathrm{pH} \geq 4$ and mean gastric $\mathrm{pH}$ after a single- and multiple-dose. Changes from baseline in the integrated gastric acidity, percentage of time with a gastric $\mathrm{pH} \geq 4$ and mean gastric $\mathrm{pH}$ were also evaluated. The integrated gastric acidity was calculated using the following method.

Acid concentration $(\mathrm{mmol} / \mathrm{L})=1000 * 10^{-\mathrm{pH}}$

Acidity $(\mathrm{mmol} * \mathrm{~h} / \mathrm{L})=(" \mathrm{t}$ " - " $\mathrm{t}-1$ ") $)$ (acid in $\mathrm{mmol} / \mathrm{L}$ at time " $\mathrm{t}$ " + acid in $\mathrm{mmol} / \mathrm{L}$ at time " $\mathrm{t}-1$ ")/2

Integrated gastric acidity $\left(\mathrm{mmol}^{*} \mathrm{~h} / \mathrm{L}\right)=\sum$ (acidity in $\mathrm{mmol} / \mathrm{L} *$ time in second)

Percent decrease from baseline in the integrated gastric acidity for a 24-hour interval after a single or multiple dose $(\%)=($ Baseline - single or multiple dose $) /$ Baseline $* 100$

\section{Safety and Tolerability Evaluation}

Safety and tolerability were evaluated throughout the study based on adverse events (AEs), physical examinations, vital signs, 12-lead ECG and clinical laboratory tests. AEs were observed throughout the study, and the investigators assessed their relationship with the treatments.

\section{Sample Size and Statistical Analysis}

Sample size was calculated based on the PK intra-subject variability $\left(\mathrm{C}_{\max }\right.$ and $\left.\mathrm{AUC}_{\text {tau }}\right)$ for esomeprazole reported in previous studies in healthy subjects. ${ }^{19-21}$ Supposing an intra-subject variability of $30.8 \%$, at least 41 subjects were required in constructing a $90 \%$ confidence interval (CI) for the geometric mean ratio (GMR) to fall within 0.8 to 1.25 with a 5\% level of confidence and $90 \%$ power. Considering possible dropouts, 44 subjects were selected as the final sample size. The PD intra-subject variability was not considered in determining the sample size because it was regarded more robust than that of the PK parameters.

Analysis of variance (ANOVA) considering the sequence, period and treatment effects as the fixed effect and subjects nested within a sequence as the random effect was used to compare the PK and PD parameters between treatments. The primary endpoint of the PK and PD was the $\mathrm{AUC}_{\text {tau }}$ after a multiple-dose and the decrease from baseline in the integrated gastric acidity after a multipledose, respectively. PK parameters were regarded as equivalent if the $90 \% \mathrm{CI}$ of the GMR was within 0.8 to 1.25. The mean difference of the PD parameters between treatments was considered not significant if the $p$-value exceeds 0.05 .

\section{Results}

\section{Study Population}

A total of 88 healthy Korean subjects were enrolled (44 subjects in each dose group). All subjects in the $20 \mathrm{mg}$ dose group completed the study, while 5 subjects withdrew their consents before administration of any treatment and 3 after several doses of either the test or reference treatment in the $40 \mathrm{mg}$ dose group. The safety analysis was conducted in 83 subjects (44 subjects in the $20 \mathrm{mg}$ dose group and 39 subjects in the $40 \mathrm{mg}$ dose group) who received a treatment at least once. The PK and PD analyses were conducted in 80 (44 subjects in the $20 \mathrm{mg}$ dose group and 36 subjects in the $40 \mathrm{mg}$ dose group) and 79 subjects (44 subjects in the $20 \mathrm{mg}$ 
dose group and 35 subjects in the $40 \mathrm{mg}$ dose group), respectively, due to loss of $\mathrm{PD}$ data in 1 subject in the $40 \mathrm{mg}$ dose group (Figure 1). The mean \pm standard deviation (SD) of the age, height, weight and BMI in the $20 \mathrm{mg}$ group were $31.1 \pm 6.9$ years, $172.7 \pm 5.3 \mathrm{~cm}, 71.4 \pm 6.9 \mathrm{~kg}$ and $23.9 \pm 1.8 \mathrm{~kg} / \mathrm{m}^{2}$, respectively, and the corresponding values in the $40 \mathrm{mg}$ dose group were $30.5 \pm 6.7$ years, $172.8 \pm$ $5.1 \mathrm{~cm}, 70.4 \pm 9.4 \mathrm{~kg}$ and $23.5 \pm 2.5 \mathrm{~kg} / \mathrm{m}^{2}$, respectively.

\section{Pharmacokinetics}

The overall pharmacokinetic characteristics of AD-206 were similar to those of the conventional esomeprazole except for the $\mathrm{T}_{\max }$. AD-206 was rapidly absorbed compared to the conventional esomeprazole. The $t_{1 a g}$ of AD-206 ranged from 0 to 1.17 hours which was shorter than that of the conventional esomeprazole of 0 to 3 hours. In addition, the $T_{\max }$ of AD-206 ranged from 0.33 to 2.5 hours after a single-dose and 0.17 to 2.5 hours after a multiple-dose which was also shorter than that of the conventional esomeprazole of 0.75 to 4 hours (Figure 2A and B). The systemic exposure of esomeprazole in AD-206 was similar to that of the conventional esomeprazole after a multiple-dose. The GMR $(90 \%$ $\mathrm{CI})$ of AD-206 to the conventional esomeprazole in terms of the $\mathrm{AUC}_{\text {tau }}$ after a multiple-dose at a steady state was 0.9359
$(0.8861-0.9885)$ in the $20 \mathrm{mg}$ dose group and 0.9849 (0.9332-1.0396) in the $40 \mathrm{mg}$ dose group (Table 1).

\section{Pharmacodynamics}

The mean gastric $\mathrm{pH}$ for AD-206 increased more rapidly compared to the conventional esomeprazole (Figures $3 \mathrm{~A}$ and $\mathrm{B}$ and $4 \mathrm{~A}$ and $\mathrm{B}$ ). The mean time to reach $\mathrm{pH} \geq 4$ after a single-dose of AD-206 was 57.77 and 35.44 minutes in the 20 and $40 \mathrm{mg}$ dose groups, respectively, compared to 89.48 and 94.84 minutes for the conventional esomeprazole (Table 2). The mean time to reach a $\mathrm{pH} \geq 4$ after a multipledose of AD-206 was also faster with 12.29 and 9.04 minutes in the 20 and $40 \mathrm{mg}$ dose groups, respectively, compared to the 22.81 and 16.54 minutes for the conventional esomeprazole. Percent decrease from baseline in the integrated acidity for a 24-hour interval of AD-206 after a multiple-dose was not significantly different compared to that of the conventional esomeprazole for both doses. The GMR (90\% CI) of AD-206 to conventional esomeprazole in percent decrease from baseline in the integrated acidity for a 24-hour interval after a multiple-dose was $1.0330(0.9783-1.0907)$ in the $20 \mathrm{mg}$ dose group and 1.0193 (0.9849-1.0549) in the $40 \mathrm{mg}$ dose group. Other PD parameters were similar between the treatments after a multiple-dose.

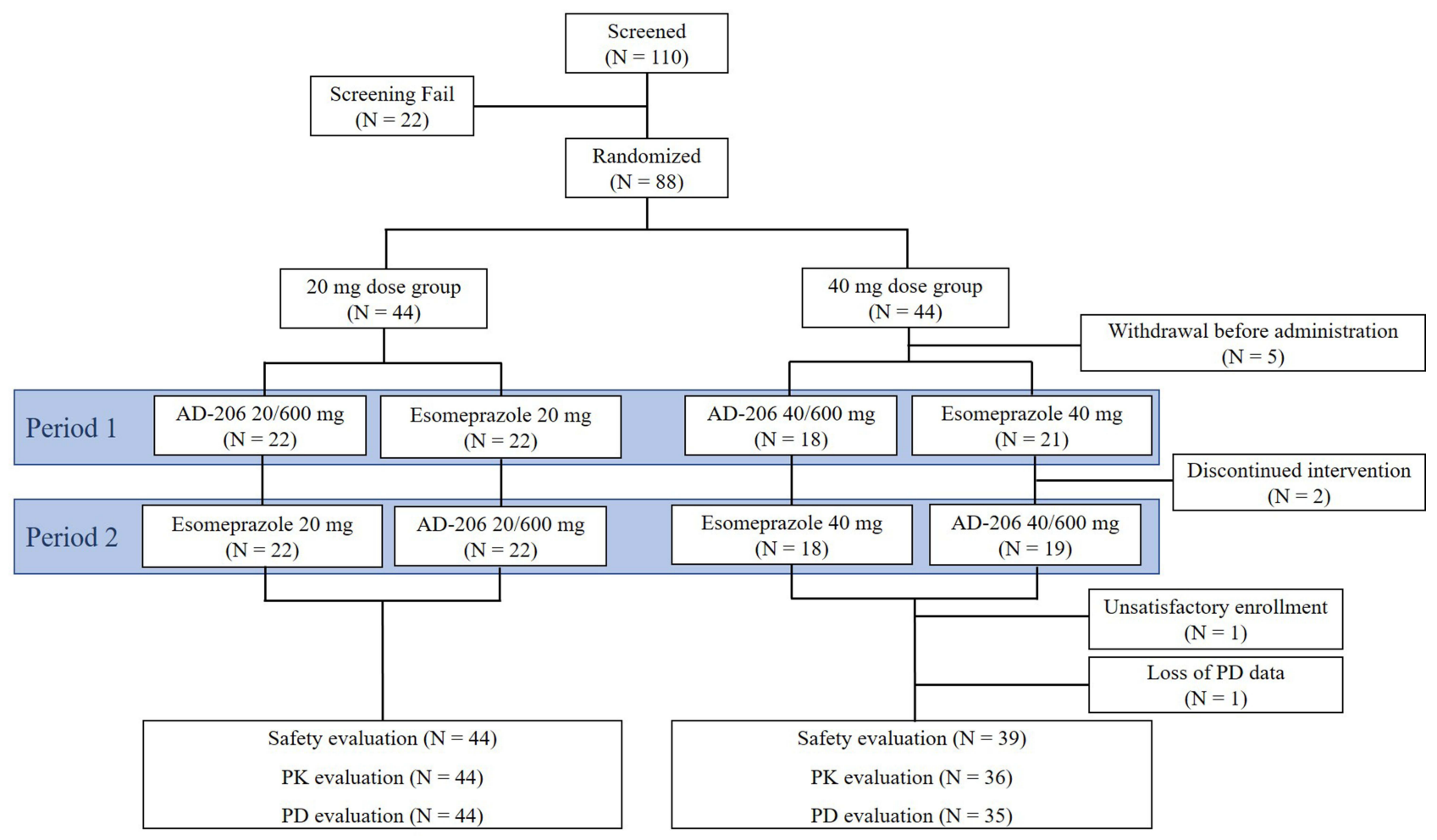

Figure I Study disposition. 
A

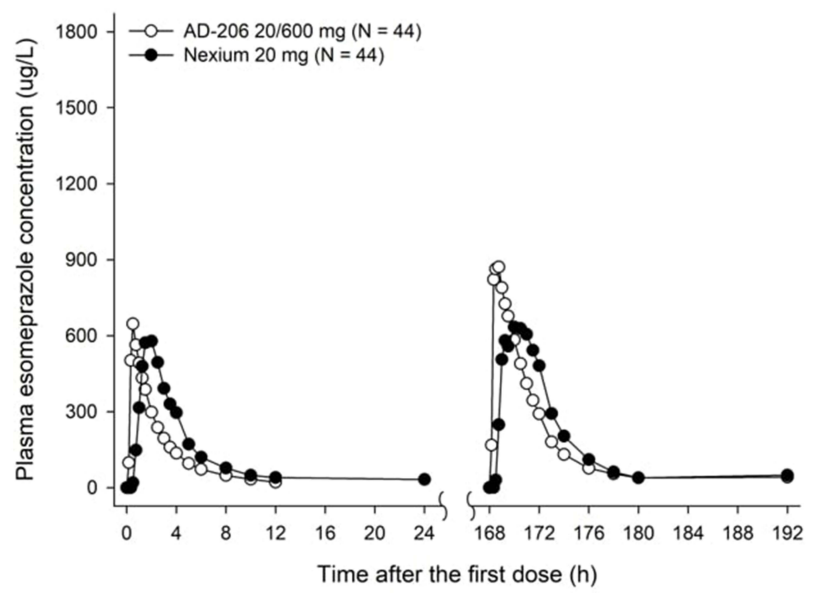

B

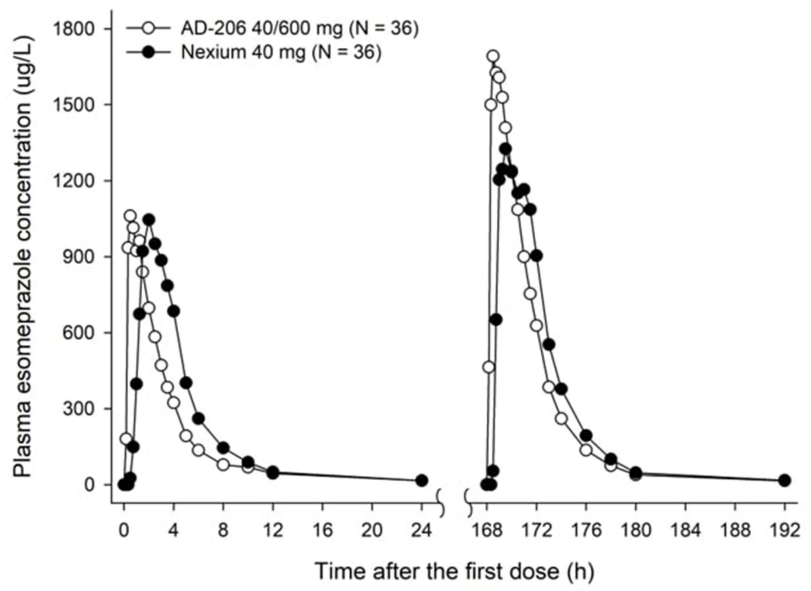

Figure 2 Mean plasma concentration-time profiles of esomeprazole in AD-206 and Nexium ${ }^{\circledR}$ after single- and multiple-dose in the (A) $20 \mathrm{mg}$ dose group and the (B) $40 \mathrm{mg}$ dose group.

\section{Safety and Tolerability}

No serious AEs (SAEs) were reported. Thirteen AEs in 5 subjects for AD-206 and 16 AEs in 9 subjects for the conventional esomeprazole were considered to be related to the treatments in the $20 \mathrm{mg}$ dose group. Moreover, 11 AEs in 7 subjects for AD-206 and 6 AEs in 3 subjects for the conventional esomeprazole were considered to be related to the treatments in the $40 \mathrm{mg}$ dose group (Supplementary Table 1). All the AEs were mild, and all subjects recovered without any complications. There were no clinically significant changes in clinical laboratory tests, 12-lead ECG, physical examination and vital signs.

\section{Discussion}

The absorption of AD-206 was faster in that the median $\mathrm{t}_{\mathrm{lag}}$ and $\mathrm{T}_{\max }$ were 0.5 to 1.5 hours shorter than those of the conventional esomeprazole. This trend was observed both after a single- and multiple-dose at steady state and in other fixed dose combinations of PPIs and $\mathrm{NaHCO}_{3} .{ }^{14,15}$ Previous studies indicated that the gastric emptying rate increases as the size of the non-disintegrating drugs gets smaller. $^{22,23}$ Similarly, formulations developed for faster disintegration compared to the conventional ones showed a more rapid absorption in several clinical studies. ${ }^{24-27}$ The rapid disintegration and earlier transition to the intestine of AD-206 could have been attributed to a faster absorption compared to the conventional esomeprazole. Additionally, the increased gastric absorption of esomeprazole with alkalinizing agents compared to the delayedrelease esomeprazole was shown in an animal model. ${ }^{28}$
Therefore, the increased gastric absorption of esomeprazole in AD-206 could have contributed to a faster absorption. It has been suggested that the plasma concentration is closely related to the inhibitory effects of PPIs. ${ }^{29}$ Likewise, AD-206 showed a faster onset of action as seen by the shorter time to reach $\mathrm{pH} \geq 4$. The time to reach a $\mathrm{pH} \geq 4$ was greatly reduced in AD-206 after a single- and multiple-dose for both doses. The faster absorption of esomeprazole in AD-206 compared to the conventional esomeprazole could have initiated the neutralization of gastric acid more quickly. Moreover, the instant release of the antacid salt $\left(\mathrm{CaCO}_{3}\right)$ might have attributed to the antacid effect. In a previous study, it was suggested that stimulation of gastrin by an antacid salt could have led to the rapid onset of the antisecretory effect. ${ }^{14}$ Given such characteristics of AD-206, it can be an alternative to conventional enteric-coated PPIs when rapid absorption or immediate management of symptoms for GERD is needed. ${ }^{30,31}$

The systemic exposure of esomeprazole for AD-206 was similar to that of the conventional esomeprazole and satisfied the predetermined equivalent criteria after a multiple-dose for both doses. However, the systemic exposure of esomeprazole in AD-206 was lower than that of the conventional esomeprazole after a single-dose for both doses. Regarding the acid-labile characteristic of esomeprazole, the gastric acidity might not have been adequately neutralized to protect esomeprazole from being degraded. Nevertheless, the PD effects after a single-dose were similar between two treatments. Also, 


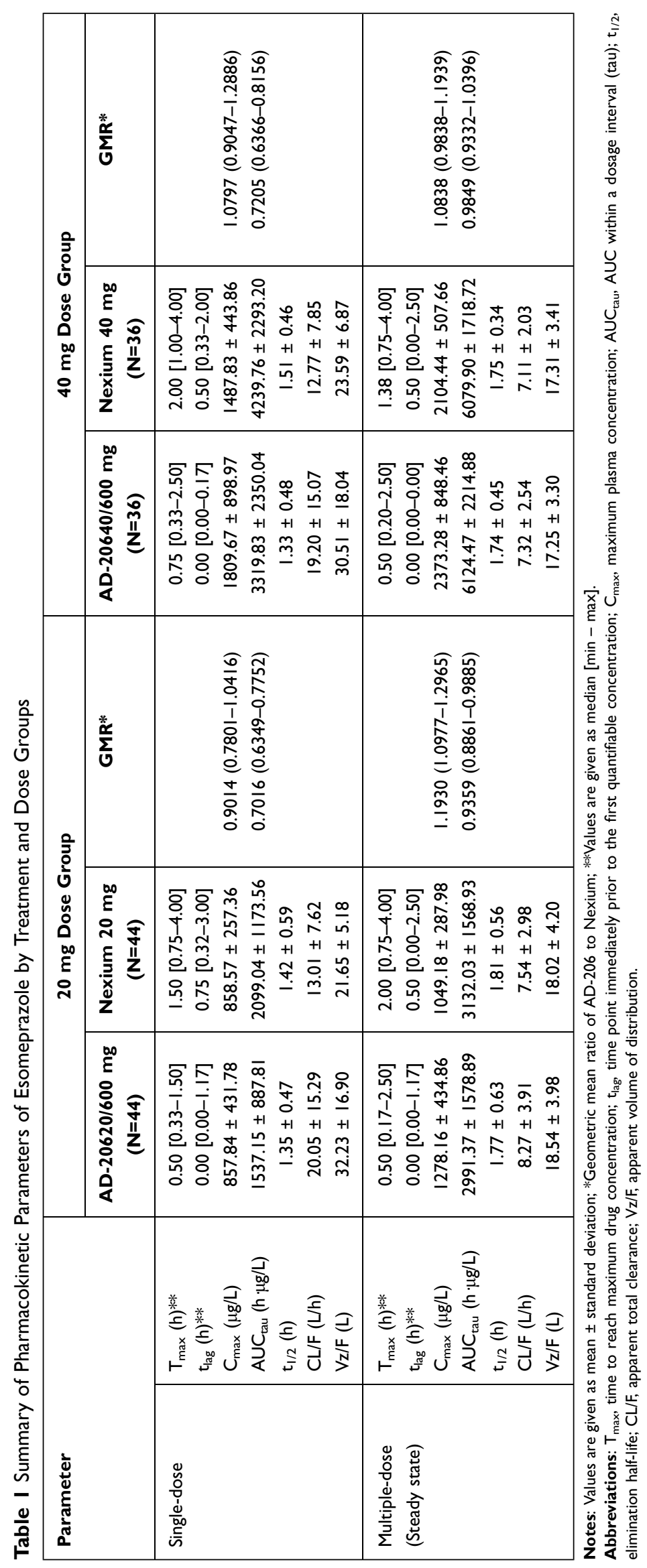



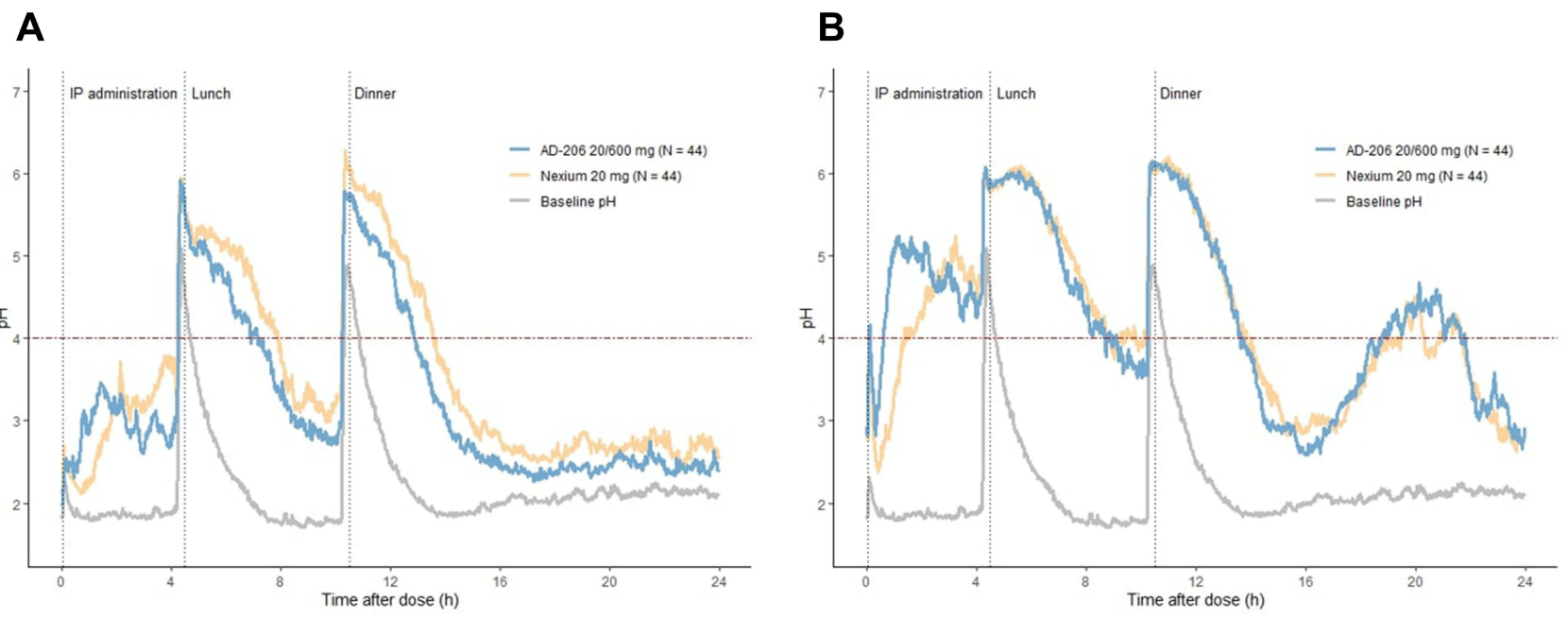

Figure 3 Mean gastric $\mathrm{pH}$-time profiles after administration of AD-206 and Nexium in the $20 \mathrm{mg}$ dose group after (A) single- and (B) multiple-dose. Notes: Baseline $\mathrm{pH}$ was calculated as the mean of baseline intragastric $\mathrm{pH}$ measured between two periods. Subjects received treatments with $\mathrm{I} 50 \mathrm{~mL}$ of water. In baseline intragastric $\mathrm{pH}$ monitoring, only $150 \mathrm{~mL}$ of water was received.
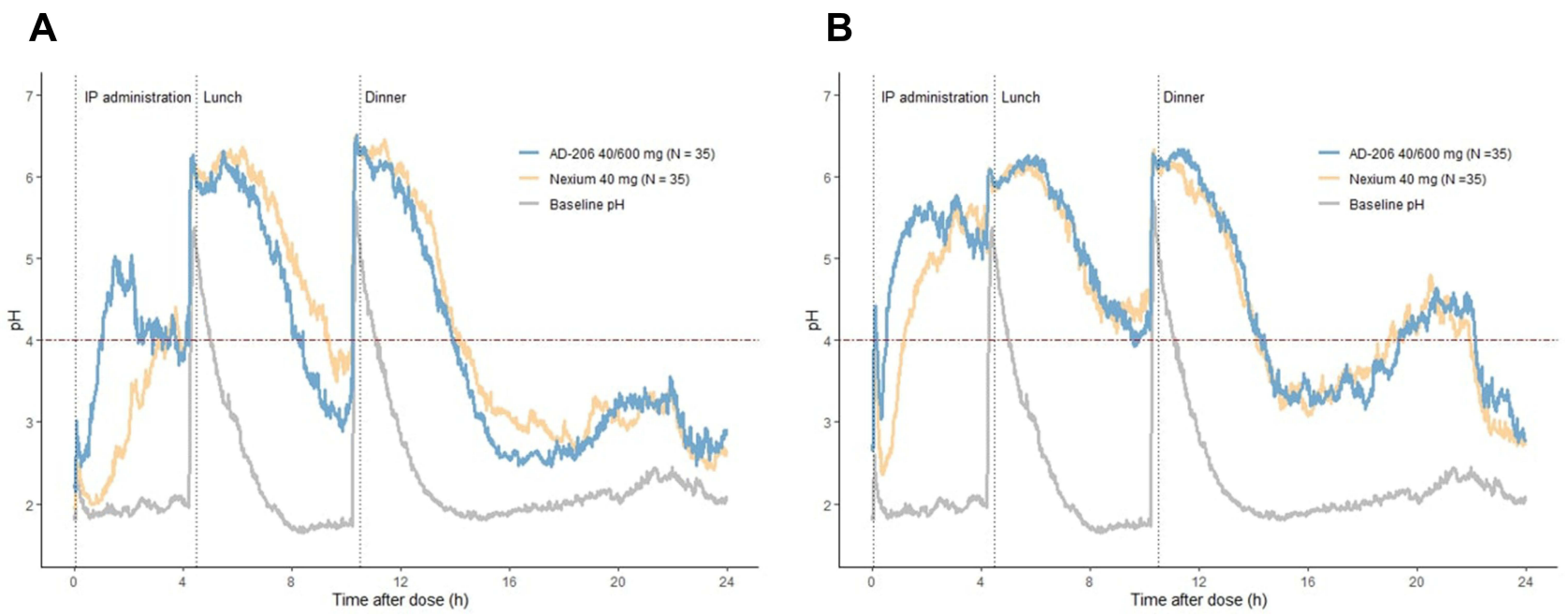

Figure 4 Mean gastric $\mathrm{pH}$-time profiles after administration of AD-206 and Nexium in the $40 \mathrm{mg}$ dose group after (A) single and (B) multiple-dose. Notes: Baseline $\mathrm{pH}$ was calculated as the mean of baseline intragastric $\mathrm{pH}$ measured between two periods. Subjects received treatments with $\mathrm{I} 50 \mathrm{~mL}$ of water. In baseline intragastric $\mathrm{pH}$ monitoring, only $150 \mathrm{~mL}$ of water was received.

considering that esomeprazole was not approved for ondemand uses and is required to be administered for at least 4 weeks, the relatively lower value of $\mathrm{AUC}_{\mathrm{tau}}$ of $\mathrm{AD}-206$ compared to that of the conventional esomeprazole after a single-dose would not have significant clinical meaning. ${ }^{32}$

Meanwhile, a higher $\mathrm{C}_{\max }$ for AD-206 can provoke safety concerns. The $\mathrm{C}_{\max }$ of AD-206 was similar in the $20 \mathrm{mg}$ dose group after a single-administration but was higher than the conventional esomeprazole after a multiple-dose in the $40 \mathrm{mg}$ dose group. Nonetheless, PPIs are a remarkably well-tolerated class of drugs, and no evidence of increased toxicity was reported among poor metabolizers despite a higher plasma concentration. ${ }^{33}$ In addition, the frequency and characteristics of the AEs were similar between the test and reference treatments, and there was no SAE in both treatments. Therefore, it is reasonable to conclude that AD-206 is as tolerable as the conventional esomeprazole regardless of the increased $\mathrm{C}_{\max }$.

Percent decrease from baseline in the integrated acidity was used as a parameter for comparing the PD effects in previous studies. ${ }^{15,16,34}$ It compares the acidity of the baseline and after a single- or multiple-dose. Considering that 


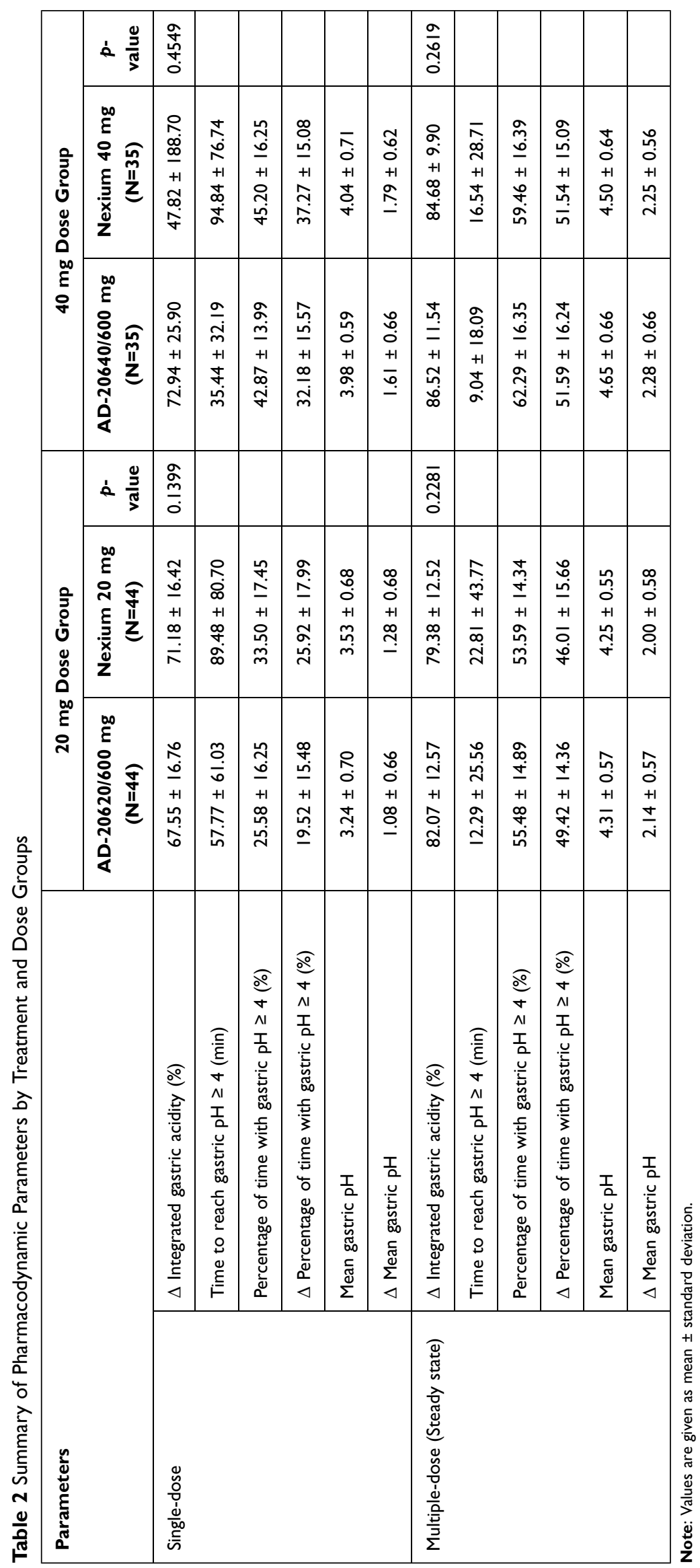


only about $2 / 3$ of the proton pumps are inhibited after a single PPI dose, anticipation of the variability of the parameter after a single-dose was expected to be demanding. ${ }^{35}$ Therefore, percent decrease from baseline in the integrated acidity after a multiple-dose was set as the primary PD endpoint in this study.

The superior acid-neutralizing capacity of $\mathrm{CaCO}_{3}$ compared to $\mathrm{NaHCO}_{3}$ enabled the development of a fixed dose combination of esomeprazole with less amount of antacid salt. In previous studies, $800 \mathrm{mg}$ and $1100 \mathrm{mg}$ of $\mathrm{NaHCO}_{3}$ were used compared to only $600 \mathrm{mg}$ of $\mathrm{CaCO}_{3}$ in $\mathrm{AD}$ 206. ${ }^{15,16}$ Development of fixed dose combination medication with smaller size is expected to improve patients' compliance and adherence.

\section{Conclusion}

AD-206 showed a similar systemic exposure and suppression of gastric acid secretion at steady state after 7 consecutive-day oral doses compared to the conventional esomeprazole. Rapid absorption of AD-206 enabled a faster onset of inhibitory action and is expected to replace the conventional esomeprazole with an earlier symptom-free condition in GERD patients.

\section{Acknowledgments}

This study was sponsored by Addpharma Pharmaceutical Corp., Korea. The investigation was conducted at the Clinical Trials Center, Seoul National University Hospital.

\section{Disclosure}

The authors report no conflicts of interest in this work.

\section{References}

1. Vakil N, van Zanten SV, Kahrilas P, Dent J, Jones R. The Montreal definition and classification of gastroesophageal reflux disease: a global evidence-based consensus. Am J Gastroenterol. 2006;101 (8):1900-20;quiz 1943. doi:10.1111/j.1572-0241.2006.00630.x

2. Dent J, El-Serag HB, Wallander MA, Johansson S. Epidemiology of gastro-oesophageal reflux disease: a systematic review. Gut. 2005;54 (5):710-717. doi:10.1136/gut.2004.051821

3. Scarpignato C, Gatta L, Zullo A, et al. Effective and safe proton pump inhibitor therapy in acid-related diseases - a position paper addressing benefits and potential harms of acid suppression. BMC Med. 2016;14 (1):179. doi:10.1186/s12916-016-0718-z

4. James OF, Parry-Billings KS. Comparison of omeprazole and histamine H2-receptor antagonists in the treatment of elderly and young patients with reflux oesophagitis. Age Ageing. 1994;23(2):121-126. doi:10.1093/ageing/23.2.121

5. Koop H, Schepp W, Dammann HG, Schneider A, Lühmann R, Classen M. Comparative trial of pantoprazole and ranitidine in the treatment of reflux esophagitis. Results of a German multicenter study. J Clin Gastroenterol. 1995;20(3):192-195. doi:10.1097/00004836199504000-00005
6. Jee SR, Seol SY, Kim DH, et al. [A randomized, comparative study of rabeprazole vs. ranitidine maintenance therapies for reflux esophagitis-multicenter study]. Korean $J$ Gastroenterol. 2005;45 (5):321-327. Korean.

7. Norman Hansen A, Bergheim R, Fagertun H, Lund H, Moum B. A randomised prospective study comparing the effectiveness of esomeprazole treatment strategies in clinical practice for 6 months in the management of patients with symptoms of gastroesophageal reflux disease. Int J Clin Pract. 2005;59(6):665-671. doi:10.1111/ j.1368-5031.2005.00564.x

8. Park CH, Lee SK. [Gastroesophageal Reflux Disease]. Korean $J$ Gastroenterol. 2019;73(2):70-76. Korean. doi:10.4166/ kjg.2019.73.2.70

9. Qi Q, Wang R, Liu L, Zhao F, Wang S. Comparative effectiveness and tolerability of esomeprazole and omeprazole in gastro-esophageal reflux disease: a systematic review and meta-analysis. Int J Clin Pharmacol Ther. 2015;53(10):803-810. doi:10.5414/cp202396

10. Tutunji MF, Qaisi AM, El-Eswed B, Tutunji LF. An in vitro investigation on acid catalyzed reactions of proton pump inhibitors in the absence of an electrophile. Int J Pharm. 2006;323(1-2):110-116. doi:10.1016/j.ijpharm.2006.05.057

11. Van Nguyen H, Baek N, Lee BJ. Enhanced gastric stability of esomeprazole by molecular interaction and modulation of microenvironmental $\mathrm{pH}$ with alkalizers in solid dispersion. Int $J$ Pharm. 2017;523(1):189-202. doi:10.1016/j.jpharm.2017.03.047

12. Horn JR, Howden CW. Review article: similarities and differences among delayed-release proton-pump inhibitor formulations. Aliment Pharmacol Ther. 2005;22(Suppl 3):20-24. doi:10.1111/j.13652036.2005.02714.x

13. Castell D. Review of immediate-release omeprazole for the treatment of gastric acid-related disorders. Expert Opin Pharmacother. 2005;6 (14):2501-2510. doi:10.1517/14656566.6.14.2501

14. Howden CW. Review article: immediate-release proton-pump inhibitor therapy-potential advantages. Aliment Pharmacol Ther. 2005;22 (Suppl 3):25-30. doi:10.1111/j.1365-2036.2005.02709.x

15. Kim D, Park MS, Yoo BW, Hong T, Park SJ, Kim CO. The safety, pharmacodynamics, and pharmacokinetics of immediate-release formulation containing esomeprazole $20 \mathrm{mg} /$ sodium bicarbonate $800 \mathrm{mg}$ in healthy adult male. Drug Des Devel Ther. 2019;13:3151-3159. doi:10.2147/dddt.S212491

16. Jing S, Zhu Y, Liu W, et al. Pharmacokinetics and pharmacodynamics of esomeprazole/sodium bicarbonate immediate-release capsules in healthy Chinese volunteers: a cross-over, randomized controlled trial. Adv Ther. 2021;38(3):1660-1676. doi:10.1007/s12325-021-01644-7

17. Washington N. Antacids and Anti Reflux Agents. Taylor \& Francis; 1991.

18. Brunton L, Chabner BA, Knollman B. Goodman and Gilman's the Pharmacological Basis of Therapeutics. 12th ed. McGraw-Hill Education; 2011.

19. Sostek MB, Chen Y, Andersson T. Effect of timing of dosing in relation to food intake on the pharmacokinetics of esomeprazole. $\mathrm{Br} \mathrm{J}$ Clin Pharmacol. 2007;64(3):386-390. doi:10.1111/j.1365-2125.2007.02889.x

20. Ullah MA, Shams UD, Maruf AA, et al. Relative bioavailability and pharmacokinetic properties of two different enteric formulations of esomeprazole in healthy bangladeshi male volunteers: an open-label, single-dose, randomized-sequence, two-way crossover study. Clin Ther. 2010;32(7):1419-1426. doi:10.1016/j.clinthera.2010.07.007

21. Islam MS, Akter N, Shohag H, et al. Bioequivalence evaluation of two esomeprazole $20 \mathrm{mg}$ capsule formulations in healthy male Bangladeshi volunteers. J Bioequiv Availab. 2011;3(6):139-143. doi:10.4172/jbb. 1000074

22. Kaniwa N, Aoyagi N, Ogata H, Ejima A, Motoyama H, Yasumi H. Gastric emptying rates of drug preparations. II. Effects of size and density of enteric-coated drug preparations and food on gastric emptying rates in humans. J Pharmacobiodyn. 1988;11(8):571-575. doi:10.1248/bpb1978.11.571 
23. Khosla R, Davis SS. The effect of tablet size on the gastric emptying of non-disintegrating tablets. Int $J$ Pharm. 1990;62(2):R9-R11. doi:10.1016/0378-5173(90)90243-W

24. Kelly K, O'Mahony B, Lindsay B, et al. Comparison of the rates of disintegration, gastric emptying, and drug absorption following administration of a new and a conventional paracetamol formulation, using gamma scintigraphy. Pharm Res. 2003;20(10):1668-1673. doi:10.1023/a:102615582212

25. Walls C, Lewis A, Bullman J, et al. Pharmacokinetic profile of a new form of sumatriptan tablets in healthy volunteers. Curr Med Res Opin. 2004;20(6):803-809. doi:10.1185/030079904125003584

26. Sheftell FD, Dahlöf CG, Brandes JL, Agosti R, Jones MW, Barrett PS. Two replicate randomized, double-blind, placebo-controlled trials of the time to onset of pain relief in the acute treatment of migraine with a fast-disintegrating/rapid-release formulation of sumatriptan tablets. Clin Ther. 2005;27(4):407-417. doi:10.1016/j.clinthera.2005.04.003

27. Shoukri RA, Ahmed IS, Shamma RN. In vitro and in vivo evaluation of nimesulide lyophilized orally disintegrating tablets. Eur J Pharm Biopharm. 2009;73(1):162-171. doi:10.1016/j.ejpb.2009.04.005

28. Benetti C, Flammini L, Vivo V, et al. Esomeprazole immediate release tablets: gastric mucosa ex vivo permeation, absorption and antisecretory activity in conscious rats. $J$ Control Release. 2016;239:203-210. doi:10.1016/j.jconrel.2016.08.032

29. Shi S, Klotz U. Proton pump inhibitors: an update of their clinical use and pharmacokinetics. Eur J Clin Pharmacol. 2008;64(10):935-951. doi:10.1007/s00228-008-0538-y
30. Katz PO, Koch FK, Ballard ED, et al. Comparison of the effects of immediate-release omeprazole oral suspension, delayed-release lansoprazole capsules and delayed-release esomeprazole capsules on nocturnal gastric acidity after bedtime dosing in patients with night-time GERD symptoms. Aliment Pharmacol Ther. 2007;25 (2):197-205. doi:10.1111/j.1365-2036.2006.03191.x

31. Wo JM, Eversmann J, Mann S. Pharmacokinetic profile of immediate-release omeprazole in patients with gastro-oesophageal reflux associated with gastroparesis. Aliment Pharmacol Ther. 2010;31(4):516-522. doi:10.1111/j.1365-2036.2009.04203.x

32. Nexium (Esomeprazole magnesium) [package insert]. U.S. Food and Drug Administration, AstraZeneca Co.; November 2020. Available from: https://www.accessdata.fda.gov/scripts/cder/daf/index.cfm? event $=$ overview.process \&ApplNo $=021957$. Accessed December 10 , 2021.

33. Gardiner SJ, Begg EJ. Pharmacogenetics, drug-metabolizing enzymes, and clinical practice. Pharmacol Rev. 2006;58 (3):521-590. doi:10.1124/pr.58.3.6

34. Kim KN, Yang SW, Kim H, Kwak SS, Kim YS, Cho DY. Acid inhibitory effect of a combination of omeprazole and sodium bicarbonate (CDFR0209) compared with delayed-release omeprazole $40 \mathrm{mg}$ alone in healthy adult male subjects. Clin Pharmacol Drug Dev. 2018;7(1):53-58. doi:10.1002/cpdd.331

35. Strand DS, Kim D, Peura DA. 25 years of proton pump inhibitors: a comprehensive review. Gut Liver. 2017;11(1):27-37. doi:10.5009/ gnl15502

\section{Publish your work in this journal}

Drug Design, Development and Therapy is an international, peerreviewed open-access journal that spans the spectrum of drug design and development through to clinical applications. Clinical outcomes, patient safety, and programs for the development and effective, safe, and sustained use of medicines are a feature of the journal, which has also been accepted for indexing on PubMed Central. The manuscript management system is completely online and includes a very quick and fair peer-review system, which is all easy to use. Visit http://www dovepress.com/testimonials.php to read real quotes from published authors. 